\title{
Okulda Sağlık Eğitimi Yoluyla Beslenme Ve Bedensel Etkinlik Davranış Değişimi
} BEHAVIOR CHANGE FOR NUTRITION AND PHYSCIAL ACTIVITIES THROUGH HEALTH EDUCATION AT SCHOOL

\author{
Seval CAMBAZ ULAŞ ${ }^{1}$, Türkan GÜNAY ${ }^{2}$ \\ Celal Bayar Üniversitesi Sağlık Yüksek Okulu Ebelik Bölümü \\ Dokuz Eylül Üniversitesi Tıp Fakültesi Halk Sağıı̆ı Anabilim Dalı
}

\begin{abstract}
öz
Okul çağındaki çocuklar yetersiz dengesiz beslenme ve sedanter yaşam alışkanlıklarından en çok etkilenen grupların başında gelmektedir. Öğün atlama, şeker, tuz ve yağ içeriği yüksek yiyecek-içecek tüketimi, televizyon ve bilgisayar başında uzun zaman geçirmek bu uygulamaların başında yer almaktadır. Çocukluk dönemindeki bu yanlış beslenme uygulamaları büyüme gelişme geriliği ve obezitenin nedenlerindendir. Ayrıca uzun dönemde sedanter yaşamın diyabet, kolon kanseri, yüksek kan basıncı ve kolestrol gelişmesi riskini arttırdığı yapılan çalışmalarla desteklenmektedir. Okullarda yapılacak sağlık eğitimi konuları çocukların yaşına, zeka düzeylerine ve gereksinimlerine göre belirlenmelidir. Sağlık eğitimi çalışmalarında bilgi ile davranış bütünleştirilmelidir. Böylece çocukların sağlıkla ilgili kavramları daha iyi anlamaları sağlanabileceği gibi, tüm yaşantıları boyunca gerekli olacak bazı davranış biçimlerini benimsemeleri de gerçekleşebilir. Etkili sağlık eğitimi programları sınıf odaklıdır. Tüm okul personelinin katılımıyla, aileye ve topluma ulaşmanın yollarını da içermelidir. Sağlık eğitimi konuları katılımcı ve karşılıklı etkileşimi sağlayıcı eğitim teknikleriyle sunulmalıdır. Aynı zamanda sağlık eğitimi programları davranışı etkileyen hazırlayıcı, olanak sağlayıcı ve güçlendirici faktörlerle öğrenme deneyimlerini birleştirmelidir. Çünkü yüksek derecede güdülenmiş ve güçlendirilmiş bir davranış eğer olanaklı kılınmaz ise önlenecek ve yapılmayacaktır. Bu nedenle okul çağındaki çocukların sağlık eğitimlerinde sadece bilgi, tutum ve becerilere odaklanan programlar yerine davranışları olanaklı kılıcı faktörleri ortaya çıkaran, olumlu sağlık davranışlarını güçlendirmeyi sağlayan yöntemler ve araç-gereç ile donanmış programlar hazırlanmalıdır.
\end{abstract}

Anahtar sözcükler: Sağlık eğitimi, beslenme, bedensel etkinlik

\section{ABSTRACT}

Seval CAMBAZ ULAŞ

Celal Bayar Üniversitesi

Sağlik Yüksek Okulu

Ebelik Bölümü

MANISA
One of the main groups which effected from malnutrition, unbalanced diets and sedentary habits is school age children. Skipping meals, consuming foods that have more sugar, salt and fat, spending more time with television and computer are mainly sedentary habits. These malnutrition habits in childhood are the reasons of growth retardation and obesity. Studies are also supported the findings that sedentary life style causes increasing risks for diabetes, colon cancer, high blood pressure and occurrence 
of cholesterol. Heath education topics at schools should be established according to ages, intelligent levels and needs of children. Knowledge and practice should be integrated in these health education activities. By this way, it provides to better understanding for health concepts and adopting some behavior styles for lifelong habits. Effective health education programs are focused on classroom. But also it should concern with reached to families and society by attendance of all school personals. Health education issues should be presented by participating and interactive education techniques. Also, health education program should integrate the preparing, enabling and strengthen factors which effect behaviors of person. If a highly motivated and strengthened behavior could not be achieved; this would be precluded and wouldn't be performed. Therefore, the programs include the methods and tools for uncovering the factors that enabled behavior changing and strengthened the positive health habits should be arranged, instead of health education programs for school-age children that focused on knowledge, behaviors and skills.

Keywords: Health education, nutrition, physical activity

Okul çağındaki çocuklar yetersiz ve dengesiz beslenmeden en çok etkilenen grupların başında gelmektedir (13). Çocukluk döneminde yeterli ve dengeli beslenme özellikle önemli olmasına karşın; bu dönemde yanlış beslenme alışkanlıklarının çok yaygın olduğu bilinmektedir. Öğün atlama, şeker, tuz ve yağ içeriği yüksek fast food olarak tanımlanan yiyecek-içecek tüketimi bu uygulamaların başında yer almaktadır. Yanlış beslenme uygulamaları büyüme gelişme geriliği ve obezitenin temel nedeni, kalp hastalıkları, hipertansiyon gibi hastalıklar içinde temel risk faktörüdür (4). Özellikle çocukluk çağı obezitenin tüm dünyada ciddi bir sorun olduğu görülmektedir. Dünyada 5-17 yaş arası en az 155 milyon çocuk fazla kilolu durumdadır. Bu çocukların 45 milyonunu ise obez çocuklar oluşturmaktadır (5). Eğer etkili önleyici çözümler uygulanmazsa, 2010 yılı itibariyle okul çağı çocuklarda obezite prevelansının şu anki oranının iki katına çıkacağı tahmin edilmektedir (6,7). “Türkiye'de ise yapılan çeşitli araştırmalara göre çocuklarda obezite prevelansının \%1,9 ile \%30,7 arasında değiştiği" bildirilmektedir (8).

Sağlıkla ilgili birçok davranış biçimini çocuklar okul yıllarında kazanırlar (2). Bedensel etkinlik davranışı da bunlardan biridir. "Enerji harcamasıyla sonuçlanan tüm bedensel hareketler (ev işleri, alışveriş gibi günlük rutin etkinlikler) bedensel etkinlik olarak tanımlanır" (9). Düzenli yapılan bedensel etkinlik çocuklarda sağlıklı bir kemik yapısını, güçlü bir kas sistemini, obezitenin kontrolünü ve önlenmesini, yağ oranının azaltılmasını, kalp ve akciğerlerin etkin bir şekilde gelişmesini sağlar (10-12). Ancak "tüm dünyada endüstrinin makineleşmesi, evlerde iş kolaylaştırma aletlerinin çoğalması, ulaşım kolaylıkları, araba kullanımının ve televizyon-bilgisayar karşısında geçirilen sürelerin artması, bedensel etkinliklerin, enerji harcanmasının azalmasına ve beslenme alışkanlıklarının değişmesine yol açmaktadır" (13). Uzun dönemde sedanter yaşamın diyabet, kolon kanseri, yüksek kan basıncı ve kolestrol gelişme riski ile kalp hastalığına bağlı ölüm riskini arttırdığı yapılan çalışmalarla da desteklenmektedir $(11,12)$. Öğrenciler okuldaki saatlerde yeterince hareketlidirler. Temel problem evde bulundukları saatlerdeki sedanter yaşam alışkanlıklarıdır. En önemli tehlike televizyon ve bilgisayar başında tüm boş zamanlarını geçirmeleridir. Amerikan Pediatri Birliği de çocukların bir günde televizyon ve bilgisayar başında geçirdiği süre 2 saat ve üzerinde ise sedanter olarak kabul edilmesi gerektiğini belirtmiştir (14). Dünya Sağlık Örgütü, Avrupa Bölgesi ülkelerinde yürütülen “Okul Çağı Çocukların Sağlık Davranışı" (Health Behaviour in School Aged Children, HBSC) araştırmasının 2006 yılı verilerine bakıldığında, 11 yaş grubundaki öğrenciler arasında ülkelere göre farklılık göstermekle birlikte bedensel etkinlik sıklığının en az \%12 olduğu, günde iki saat üzerinde televizyon ve bilgisayar başında zaman geçirenlerin \%30 ile \%81 arasında olduğu, yaş artıkça da bu yüzdelerin arttı̆̆ı bildirilmiştir (15). Aynı araştırmanın Türkiye verilerine göre, her gün düzenli bedensel etkinlik yapma hem kız hem de erkek öğrencilerde yaş artıkça azalmaktadır. Bedensel etkinlik yapma 11 yaşındaki kızlarda \%21, erkeklerde \%29'dur. Aynı araştırmada hafta içi günde en az 2 saat üzerinde televizyon ve bilgisayar başında zaman geçirenlerin yüzdesi hem erkek hem de kız öğrencilerde yaş ile birlikte artmaktadır. 11 yaşındaki kızlarda \%59, erkeklerde \%63'tür (16). 
Çocukluk çağında başlayacak düzenli bedensel etkinlik ve sağlıklı beslenme alışkanlığı erişkinlikte sağlığın korunması için anlamlı katkılar sağlamaktadır (17). Okul dönemi çocukların beslenme ve sedanter davranışlarına bağlı sağlık risklerinin belirlenmesi, uygun sağlık eğitimlerinin planlanması ve çocukların olumlu sağlık davranışlarını geliştirmeleri açısından önemlidir. $\mathrm{Bu}$ derlemede çocukların yeterli dengeli beslenme ve bedensel etkinlik konusunda olumlu davranış değişimini sağlamak için verilecek sağlık eğitiminin özelliklerinden ve Türkiye'deki var olan uygulamalardan söz edilecektir.

\section{OKULDA DAVRANIŞ DEĞİŞiKLİĞİ OLUŞTURMAYA YÖNELIK SAĞLIK EĞİTIMI NASIL OLMALI?}

Okul sağlığı hizmetlerinde amaç; toplumda okul çağındaki bütün çocukların olabilen en iyi bedensel, ruhsal, sosyal sağlı̆̆a kavuşmalarını sağlamak ve sürdürmektir. Sağlık eğitimi okul sağlı̆̆ı hizmetlerinin en önemli basamaklarındandır $(9,18)$. Sağlık eğitimi Green tarafından; "sağlığa yönelik bireysel ve ortaklaşa davranışa, gönüllü bir şekilde uyumu hazırlamak, olanaklı kılmak ve güçlendirmek için düzenlenen öğrenme deneyimlerinin herhangi bir bileşimi" olarak tanımlanmaktadır. Sağlık eğitiminin temel amacl; "bireyin ve toplumun gereksinimlerini karş1layacak sağlıklı yaşam için kişilerin sağlıklarını korumalarını ve geliştirmelerini, tedavi olanaklarından yararlanmaları ve olumlu bir çevre yaratmalarını sağlayacak bilgi, tutum ve davranış değişikliğini oluşturmaktır" $(19,20)$.

Okulda yapılacak sağlık eğitimlerinde çocukların yaşı, zeka düzeyleri ve gereksinimleri dikkate alınmalıdır (21). İlköğretimde öğrencilere verilecek sağlık eğitimi konuları sağlıklı beslenme, bireysel temizlik (sağlığı koruma), hastalıklardan korunma, sporun yararları, temiz hava ve güneşin yararları, sağlıklı giyinme, kazalardan korunma, ilk yardım, çevre temizliği ve bakımı, bölgesel hastalıklar konularını içermelidir. Orta öğretimde ise büyüme gelişme, güvenli cinsel ilişki ve madde bağımlılı̆̆ı konuları da sağlık eğitimlerine eklenmelidir (9,22-24). Okulda sağlık eğitimi çalışmalarında bilgi ile davranış bütünleştirilmelidir. Sağlık eğitimleri öğrencilerin bireysel olarak karar verme, sosyal beceri ve kendilerine güvenmeleri yönünde desteklemelidir. Böylece çocukların sağlıkla ilgili kavramları daha iyi anlamaları sağlanabileceği gibi, tüm yaşantı- ları boyunca gerekli olacak bazı davranış biçimlerini benimsemeleri de gerçekleşebilir (25). Etkili sağlık eğitimi programları sınıf odaklı, tüm okul personelinin katılımı sağlanarak aile ve topluma ulaşmanın yollarını da içermelidir (26). Bir eğitimde, eğitmenin görevi öğrencilerde eğitimin hedefleri doğrultusunda istenilen davranış değişikliğini oluşturmaktır. Eğitimde istenilen verimin elde edilebilmesi için olumlu bir eğitim ortamının yaratılması önemlidir. Bu ise ancak ilginin sürekli kılındığı katılımcı ve karşılıklı etkileşimi sağlayıcı (interaktif) eğitim yöntemleriyle sağlanabilir. Eğitmen ve öğrenciler arasında çok yönlü iletişimi sağlayan bu yöntemler;

1. Görsel işitsel araçlarla işlenen sınıf dersi,

2. Soru yanıt yöntemi,

3. Küçük grup çalışmaları (olgu çalışması, oyunlaştırma, beyin fırtınası, grup tartışması)

\section{Proje çalışması}

\section{Gösterim}

\section{Yetiştiricilik gibi yöntemlerdir.}

Sağlık eğitimi sürecinde öğrencilerin ne kadar çok sayıda duyusuna yönelirse o oranda etkili bir öğretim sağlanmış olur (27). Böylece gerçek uygulamalar sınıf içerisine getirilerek, öğrenci gözüyle, kulağıyla ve eliyle öğrenme ortamına çekilerek öğrenmenin daha kalıcı olması sağlanmaktadır (28). Sağlık eğitiminin amacı öğrencilerin belli bir konuda "bilgi kazanması" ise, görsel-işitsel araçlarla bir sınıf dersi, tartışma gibi yöntemler seçilebilir. Amaç, öğrencilerin bir konuda "davranış değiştirmesi" ise daha çok tartışma, oyunlaştırma, olgu çalışması, proje geliştirme, yetiştiricilik gibi yöntemler kullanılmalıdır (29).

“Etkili bir sağlı eğitimi programı, aşağıdaki önerileri içermelidir.

1. Kapsamlı ve olumlu sağlık davranışları üzerine odaklı olmalıdir.

2. Uygulamayı geliştirmelidir.

3. Longitüdinal ve farklı düzeylerde dikkatlice tasarlanmalıdır.

4. Kültürel duyarlılıkları dikkate almalıdır. 
5. Okul ve sinıf odaklı olmalı ancak onlarla sinırlı kalmamalıdır.

6. Akran uygulamalarını ve becerilerini içermelidir.

7. Anne ve babalar, ev ödevleri ile sağlık davranışlarını kazandırmada etkin rol oynamalıdır.

8. Öğrencilerden anne baba, okul liderleri ve toplum liderlerine doğru bir akış izlemelidir.

9. Okulda sağlık davranışlarını destekler bir çevrenin oluşturulması desteklemelidir.

10. Tüm aşamalarında devamlı bir değerlendirme süreci olmalıdır" (30).

\section{Davranış Değiştirme Süreci Nasıl Oluşturulur?}

Sağlık eğitimi konusunda pek çok sağlık davranış modeli bulunmaktadır. Sağlık İnanç Modeli, Değişimin Aşamaları Modeli, Planlı Davranış Kuramı en çok bilinenleridir. Bu modeller sağlığı geliştirme ve sağlık eğitimi çalışmalarının planlanmasında kullanılmaktadır. Son yıllarda en çok kullanılan modellerden birisi de Precede Proceed Modeli'dir. Bu model gereksinim saptama (Precede) ve uygulama (Proceed) adımlarından oluşur. Planlamadan çok uygulamaya odaklanmasıyla diğerlerinden ayrılmaktadır (31). Özellikle ülkemizde okulda beslenme ve bedensel etkinlik konusunda davranış değiştirmeye yönelik olarak en önemli eksiklik uygulamaya yönelik girişimlerin olması nedeniyle bu derleme de tercih edilmiştir.

Sağlı̆̆ı geliştirmek için davranış değişimi sağlamada sağlık davranışını etkileyen ve eğitimsel girişimlerle değiştirilebilen üç temel faktörden söz edilmektedir.

a. Hazırlayıcı faktörler: Bilgi, tutum, inançlar, değerler ve algılamalar bu gruba girmektedir. Bunları değiştirmek için geleneksel tek yönlü didaktik eğitimlerin yerine, daha çok karşılıklı etkileşimi sağlayan (interaktif) yöntemlere gereksinim duyulur $(29,31)$.

NEAPS programında 8-10 yaş öğrencilere sağlık eğitiminin yanında aktivite çalışmaları ve ailelere beslenme günlükleri tutturulmuştur. Programın sonunda öğrencilerin beslenme bilgisinin arttığı, daha az tuzlu atıştırmalıklar, daha çok sebze ve meyve yedikleri belirlenmiştir (32).
Switch Off-Get Active çalışmasında 10 yaş öğrencilere 10 haftalık, ögrretmenlere 3 saatlik sağlık eğitimi verilmiş ve öğrencilere günlük tutturulmuştur. Projenin sonunda öğrencilerin televizyon ve bilgisayar başında geçirdikleri sürenin azaldığı ve bedensel etkinlik yapanların arttığı belirlenmiştir (33).

Ülkemizde Milli Eğitim Bakanlığı'nın müfredatında beslenme ve bedensel etkinlik konuları yer almaktadır. Ancak bu konuların derslerin içindeki işleniş şekli değiştirilerek, davranış değişikliği yapmaya yönelik etkileşimli eğitim yöntemleri kullanılarak öğrencilerin yaşlarına uygun sınıf tabanlı sağlık eğitimleri planlanmalı ve bu eğitimlere okul sağlığı bileşenleri olan öğrenci, öğretmen, aile ve okul çalışanlarının da katılımı sağlanmalıdır.

b. Olanak sağlayıcı faktörler: Sağlık davranışlarının ortaya konmasını, pratikte uygulanmasını olanaklı kılan faktörlerdir. Bunlar sağlık kurumları, çalışma alanları, okul gibi alanlarda sağlık davranışının uygulanabilir olmasını sağlar $(29,31)$.

High 5 projesinde 9-11 yaş grubundaki öğrencilere sağlık eğitimi verilmiş, sağlıklı gıdaların satılması için kafeterya ve yemekhaneye uyarı yapılmıs, aynı zamanda eğitimler aile etkinlikleriyle desteklenmiştir. Bu programin sonunda ailelerin ve öğrencilerin sebze ve meyve yemeleri artmıştır (34).

NutriActive Healthy Experience çalışmasında 6-7 yaş öğrencilere haftada iki ders 20 dakika sağlık eğitimi verilmiş, bedensel etkinlikleri arttırıcı faaliyetler programa eklenmiş ve okulda sağlıklı ara ögün dağıtımı yapılmıştır. Çalışmanın sonunda öğrenciler daha sağlıklı atıştırmalıkları seçmiştir (35).

Ülkemizdeki okullarda sağlık davranışlarını destekler bir çevre yoktur. Milli Eğitim Bakanlığı'nın 21 Temmuz 2011 tarihli ve 2011/41 sayılı Genelgesi ile gazlı içecekler ve cipslerin okul kantinlerinde satışı yasaklanarak öğrencilerin bu besinlere ulaşımı engellenmiştir (36). Bu genelge olumlu bir adım olmakla birlikte yetersizdir. Milli Eğitim Bakanlığı'nın genelgesinin içeriği genişletilerek kantinlerde sağlıklı gıdaların satışı sağlanmalı, okul kantinlerinde taze sebze, meyve satılması ve öğrencilerin bedensel etkinliğini artırıcı ortamlar oluşturulmalıdır. 
c. Güçlendirici faktörler: Sağlık eğitiminde son zamanlarda davranışı güçlendirici, pekiştirici faktörler çok yaygınlık kazanmaya başlamıştır $(29,31)$. Yeterli dengeli beslenme ve bedensel etkinlik konusunda okulda verilen bilgilerin öğretmenler, aileler, yöneticiler ve toplum tarafından aynı mesajlar ile desteklenmesidir.

Gimme 5 projesinde 9-11 yaş öğrencilere ve öğretmenlere sağlık eğitimi verilmiş aynı zamanda ev içi ve ev dışı aile aktiviteleriyle desteklenmesi sonucunda öğrencilerin sebze meyve yemeleri artmış, beslenme davranışları olumlu yönde değişmiştir (37).

Eat Well and Keep Moving programında 9 yaşındaki öğrencilerle birlikte yöneticilere, öğretmenlere, ailelere ve toplum çalışanlarına sağlık eğitimi verilmiştir. Ayrıca bedensel etkinlik çalışmalarıyla birlikte, öğrencilere sağlıklı yemek seçme eğitimleri de verilmiştir. Programın sonunda öğrencilerin daha çok sebze ve meyve yedikleri, televizyon ve bilgisayar başında daha az zaman geçirdikleri belirlenmiştir (38).

Ülkemizde ulusal okul sağlığı politikasının yokluğu önemli bir eksikliktir. Çünkü güçlendirici faktörlerin desteklenebilmesi için beslenme ve bedensel etkinlik konusunda okulda verilen tüm mesajların okul içi ve okul d1şında da desteklenmesi gerekmektedir. Bunun için de ulusal düzeyde yasal yaptırımlara gerek vardır. Bu nedenle ülkemiz için öncelikli olarak ulusal okul sağlı̆̆1 politikası oluşturulmalı, tüm okullarda devlet tarafından desteklenecek öğrencilere en az bir öğün yemek ya da ara öğün verilmeli, sedanter yaşam alışkanlıklarını azaltmaya yönelik girişimlerde bulunulmalı, ayrıca ulusal düzeyde reklamları kontrol altına alacak yasal düzenlemeler ile okul çevresinde yiyecek satışı yapan yerlerle ilgili de düzenlemeler yapılmalıdır. Okul sağlığı hizmetlerinin başarılı bir şekilde yürütülebilmesi için ekip üyelerinin disiplinler arası koordinasyon ve işbirliğine gereksinim vardır. Ayrıca bu hizmetlerin yürütülmesinde okul yöneticileri, öğretmenler ve velilerle işbirliği yapılması da gereklidir (18). Ülkemizdeki okul sağlığı hizmetlerinin yürütülmesinden Milli Eğitim Bakanlığı ve Sağlık Bakanlığı sorumludur. Bu ekip okul doktoru, okul sağlı̆̆ hemşiresi, sınıf öğretmeni, beden eğitimi öğretmeni, okul psikologu (psikolojik danışmanlık ve rehberlik uzmanı), sosyal hizmet uzmanı, diyetisyen / beslenme uzmanı ve ailelerden oluşur. Ülkemizdeki eğitim yapılanmasında okul doktoru, okul sağlığı hemşiresi, sosyal hizmet uzmanı ya da beslenme uzman bulunmamaktadır. Okul doktoru ya da okul hemşiresi ancak gerektiğinde sağlık eğitimleri, okul aşıları ya da okul taramaları vb. durumlarda çok sınırlı sürelerde okullarda bulunmaktadırlar. Beslenme ve bedensel etkinlik konusunda da sistematik bir yapılanma yoktur. Diğer ülkelerde ise eğitim sistemi içerisinde okul doktoru, okul hemşiresi, beslenme ve spor servisleri de bulunmaktadır. Böylece yapılacak tüm girişimler sadece sağlık eğitimi olarak değil okulların ilgili tüm yapılarını içine katacak şekilde planlanmaktadır. Ayrıca pek çok ülkede ulusal okul sağlığı programının varlığı da dikkati çekmektedir (39). Ülkemizde ise; beslenme ve bedensel etkinlik ile ilgili çalışmalar ilgili bakanlıkların pilot projeleri ya da üniversitelerin yerel çalışmalarıyla devam etmektedir. Sonuç olarak; okul çağı çocukların beslenme ve bedensel etkinlik davranış değişimini sağlamak için etkileşimli eğitim yöntemleri kullanılarak sağlık eğitimi vermenin yanında, öğrencilerin sağlıkla ilgili kararlarında etkili olan davranışa olanak sağlayıcı, destekleyicigüçlendirici faktörlerin de desteklenmesi özellikle önemlidir. Çünkü yüksek derecede güdülenmiş ve güçlendirilmiş bir davranış eğer olanaklı kılınmaz ise önlenecek ve yapılmayacaktır $(29,31)$.

\section{KAYNAKLAR}

1. Hayta A, Şanlıer N. İlkoğretim 6. 7. 8. sınıf öğrencilerinin beslenme davranışları ve sosyal onaylanma isteği. Milli Eğitim Dergisi 2007;174:193-205.

2. Keskin M. Yatılı ilköğretim bölge okullarında öğrencilere verilen beslenme eğitiminin besin tüketimlerine etkisinin araştırılması. Gazi Üniversitesi Eğitim Bilimleri Enstitüsü Yüksek Lisans Tezi, 2009.

3. Ünüsan N. Avrupa Birliğine üye ülkelerde beslenme eğitimi ve Türkiye için öneriler. Eğitim ve Sosyal Bilimler Dergisi 2005;33:167.

4. Küzdere Y. Çubuk ilçesi'nde iki ilköğretim okulunda okuyan üçüncü sınıf öğrencileri arasında yeterli ve dengeli beslenme konusunda bir müdahale araştırması. Hacettepe Üniversitesi Sağlık Bilimleri Enstitüsü Yüksek Lisans Tezi, 2008

5. Lobstein T, Baur L, Uauy R. Obesity in children and young people: a crisis in public health. Obesity Reviews 
2004:5:4-85.

6. Wang Y, Lobstein T. Worldwide trends on childhood overweight and obesity. International Journal of Pediatric Obesity 2006;1:11-25.

7. World Health Organization. Diet, nutrition and the prevention of chronic diseases. WHO Technical Report Series:916. Erişim adresi:

http://whqlibdoc.who.int/trs/WHO_TRS_916.pdf

Erişim tarihi: 15 Nisan 2009

8. Özçırpıcı B, Şahinöz S, Özgür S, Bozkurt İ. Gaziantep ilinde şişmanlık prevelansı. IX. Ulusal Halk Sağlığ Kongre Kitabı: 37, 2004, Ankara.

9. T.C Sağlık Bakanlığı Refik Saydam Hıfzıssıhha Merkezi Başkanlığı. Sağlık hizmetlerinde okul sağlığı kitabı. Ankara: Yücel Ofset, 2008;56-65.

10. Lee SU, Burgeson CR, Fulton SE, Spain CG. Physical education and physical activity: results from the school health policies end programs study 2006. The Journal of School Health 2007;77:435-463.

11. U.S. Department of Health and Human Services. Physical activity guidelines advisory committee report. Washington, DC:U.S. Department of Health and Human Services; 2008.

12. Mokdad AH, Ford ES, Bowman BA, et al. Prevalence of obesity, diabetes, and obesity-related health risk factors, 2001. Journal of the American Medical Association 2003;289:76-79.

13. Öztora S. İlköğretim çağındaki çocuklarda obezite prevalansının belirlenmesi ve risk faktörlerinin araştırılması. Sağlık Bakanlığı Bakırköy Dr. Sadi Konuk Eğitim ve Araştırma Hastanesi Uzmanlık Tezi, 2005.

14. American Academy of Pediatrics. Children, adolescents and television. Pediatrics 2001;107:423-426.

15. World Health Organization. Health behaviour in schoolaged children international report from the 2005/2006 survey. Erişim adresi:

http://www.euro.who.int/Document/E91416.pdf. Erişim tarihi: 5 Haziran 2009.

16. Okul Çağı Çocukların Sağlık Araştırması Türkiye 2006 Raporu. İstanbul: Üniform basım, 2009;48-55.

17. T.C Sağlık Bakanlığı Refik Saydam Hıfzıssıhha Merkezi Başkanlığı. Birinci basamak sağlık çalışanlarına yönelik okul sağlığı rehberi. Ankara: Sağlık Bakanlığı Yayını,
$2005 ; 15$.

18. Pekcan H. Okul sağlığı. Halk sağlığı temel bilgiler kitabı (1) içinde Ed: M Bertan, Ç. Güler, Hacettepe Üniversitesi Hastanesi Basımevi, Ankara 2006; 459-461.

19. Ö̈zvarış ŞB. Sağlık eğitimi ve sağlığı geliştirme. Ankara: Hacettepe Halk Sağlığı Vakfı, 2001;18-19.

20. Güler Ç, Akın A. Sağlık eğitimi ve iletişimi. Halk sağlığı temel bilgiler kitabı (1) içinde Ed: M Bertan, Çı Güler, Güneş Kitabevi Ltd. Şti, Ankara 1995; 421-432.

21. T.C Sağlık Bakanlığı Refik Saydam Hıfzıssıhha Merkezi Başkanlığı. Okullarda sağlık eğitimi: Mevcut durum. Ankara: Sağlık Bakanlığı yayını, 2005;1-7.

22. Potts L, Mandleco L. Pediatric nursing. USA: Delmar \& Thomson Learning Press; 2002.

23. Gidding S, Dennison A, Birch L, et al. Dietary recommendations for children and adolescents: a guide for practitioners. Pediatrics 2006;117:544-559.

24. Sallis F, Patrick K, Frank E, et al. Interventions in health care settings to promote healthful eating and physical activity in children and adolescents. Preventive Medicine 2000; 31:112-120.

25. Regis D. Pastoral models: Personal development and "self empowerment" in health education. Erişim adresi: http: //www. ex. ac.uk/sheu/Phd/2b.html. Erişim tarihi: 15 Mayıs 2009.

26. Özyurt B. Manisa kent merkezinde okul sağlığı düzeyinin tanımlanması. Celal Bayar Üniversitesi Tıp Fakültesi Halk Sağlığı Anabilim Dalı Uzmanlık Tezi,2004.

27. Özvarış ŞB, Demirel Ö. Öğrenen merkezli tıp eğitimi: Eğitici rehberi. Ankara: Türk Tabipler Birliği Merkez Konseyi yayını,2002.

28. Özden Y. Öğrenme ve öğretme. Ankara: Önder Matbaacllı, 1998;183.

29. Özvarış ŞB. Sağlık eğitimi ve sağlığı geliştirme. Ankara: Hacettepe Halk Sağlığı Vakfı, 2001;18-19.

30. Gürbüz K. Olumlu sağlık davranışlarının kazandırılmasında okul sağlığı hemşireliği uygulamaları. Kocaeli Üniversitesi Sağlık Bilimleri Enstitüsü Yüksek Lisans Tezi, 2006.

31. Aslan D. Sağlığın geliştirilmesinde yeterli ve dengeli beslenme: Halk sağlığı profesyonellerine yönelik bilgiler. İmir: HASUDER İzmir Çalıştay kitabı, 2009; 45-47.

32. Friel S, Kelleher C, Geraldine Nolan P. Evaluation of the 
nutrition education at primary school (NEAPS) programme. Public Health Nutrition 1999;2:549-555.

33. Harrison M, Burns CF, McGuinness C, et al. Influence of a health education intervention on physical activity and screen time in primary school children: 'Switch Off-Get Active'. Journal of Science and Medicine in Sport 2006; 9:388-394.

34. Reynolds KD, Franklin FA, Binkley D, et al. Increasing fruit and vegetable consumption of fourth-graders: results from the High 5 Project. Prev Med 2000;30:309319.

35. Matvienko O. Impact of a nutrition education curriculum on snack choices of children ages six and seven years. J Nutr Educ Behav 2007;39:281-285.

36. Milli Eğitim Bakanlığı okul kantinlerinde gıda satışı genelgesi. Erişim adresi:

http://mebk12.meb.gov.tr/meb_iys_dosyalar/34/33/74244 3/dosyalar/2013_01/14024238_okulkantinlerigenelgesi.pd

f. Erişim tarihi:21 Ağustos 2011

37. Cullen KW, Baranowski T, Rittenberry L, Olvera N. Social-environmental influences on children's diets: results from focus groups with African, Euroland, Mexican-American children and their parents. Health Educ. Res 2000a;15:581-590.

38. Gotmarker S, Cheung L, Peterson K, Chomitz G. Impact of a school-based interdisciplinary intervertion on diet and physical activity among urban primary school children. Arch Pediatr Adolesc Med 1999;153:975-983.

39. Garipağaoğlu M, Özgüneş N. Okullarda beslenme uygulamaları. Çocuk Dergisi 2008; 8:152-159. 